\title{
Negative Impact of Paclitaxel Crystallization on Hydrogels and Novel Approaches for Anticancer Drug Delivery Systems
}

\author{
Javier S. Castro1,2, Lillian V.Tapiaㄹ, Rocio A. Silveyra ${ }^{1}$, \\ Carlos A. Martinez ${ }^{1}$ and Pierre A. Deymier ${ }^{2}$ \\ ${ }^{1}$ Materials Science and Engineering, Institute of Engineering and Technology, \\ Autonomous University of Juarez City, Juarez City, Chih. \\ ${ }^{2}$ Department of Materials Science and Engineering, \\ University of Arizona, Tucson AZ 85721 \\ ${ }^{1}$ Mexico \\ ${ }^{2} U S A$
}

\section{Introduction}

Paclitaxel, better known as Taxol® its original name and now trade mark, and its direct derivatives, has been one of the most effective drugs used against tumors and cancer (Rowinsky et al., 1990; Rowinsky \& Donehower, 1995) due to its ability to stabilize microtubules in the mitotic spindle and thus stopping the cell cycle in eukaryotic cells (Wani et al.,1971). The stabilization of microtubules is due to the specific bond between Taxol ${ }^{\circledR}$ and beta tubulin preventing microtubule depolymerization (Schiff et al., 1979). It has also been reported that Taxol ${ }^{\circledR}$ inhibits the process of angiogenesis (Wang et al., 2003). These Taxol® qualities have been taken as an advantage for the usage of this drug in killing carcinogenic cells in tumors.

One of the main drawbacks of this molecule is its high hydrophobicity; making it practically insoluble in water which hinders their use in treatments inside the human body. In order to overcome such inconveniences, several strategies have been developed such as the use of adjuvants like Cremofor/Etanol (CrEL), solubilizant agent that facilitates the intravenously administration of the drug, process termed as chemotherapy. This technique has brought many disadvantages such as the fact of reducing considerably the drug's diffusion capacity, making that a limited quantity of the drug be reached into the target site (Marupudi et al., 2007), and therefore limiting the concentration level needed to eliminate tumors. To solve these inconveniences it has been resolved to increase the delivery cycles. The usage of Taxol® in CrEL and the high doses have produced undesired consequences with a numerous of hypersensitivity reactions and side effects including nausea, vomiting, urticaria, abdominal pain, diaphoresis, and other (Weiss et al., 1990; Wiernik et al., 1987). Looking for minimizing such secondary reactions, new options in the field of drug delivery are being explored. In the last decade a variety of drug delivery systems have been proposed as carriers of hydrophobic anticancer drugs. The list of these systems includes 
drug loaded hydrogels, drug loaded nanoparticles, functionalized nanoparticles and some combined systems. Through this chapter we review the current trends for the transport and delivery of the most common anticancer drugs. Based in facts we point a delicate issue, Taxol crystallization in hydrogels and its negative impact, and finally we make a discussion about novel approaches for drug delivery against cancer.

\section{Hydrogels for drug delivery systems}

Currently the development of smart hydrogels that can respond to external stimuli such as variations in temperature, $\mathrm{pH}$, and electric fields or hydrogels with controlled biodegradability has been used in biomedical applications. As such hydrogels are used in a wide range of applications including tissue engineering and regenerative medicine (Lee \& Mooney, 2001), diagnosis (Van Der Linden et al., 2003), cell immobilization (Jen et al., 1996), bimolecular and cell separation (Wang et al., 1993), barriers to regulate the biological adhesion (Bennett et al., 2003). Hydrogels can be made, in theory, from any water-soluble polymer, encompassing a wide range of chemical compositions and physical properties. The polymer forms aggregates that form a three-dimensional matrix with interconnected pores in which the solvent (usually water or aqueous solutions) and other particles can diffuse (Figure 1). Some hydrogels have a high capacity to contain compounds that can be released in a controlled manner for therapeutic purposes. Its porosity allows the loading of drugs within the polymer matrix and their subsequent release at a rate that depends on the coefficient of diffusion of drug through the gel matrix in the case of hydrophilic drugs. For hydrophobic drugs, the rate of release depends on the rate of degradation of the gel. Besides their biodegradability can be designed to be via enzymatic, hydrolytic, or environmental ( $\mathrm{pH}$, temperature or electric fields).
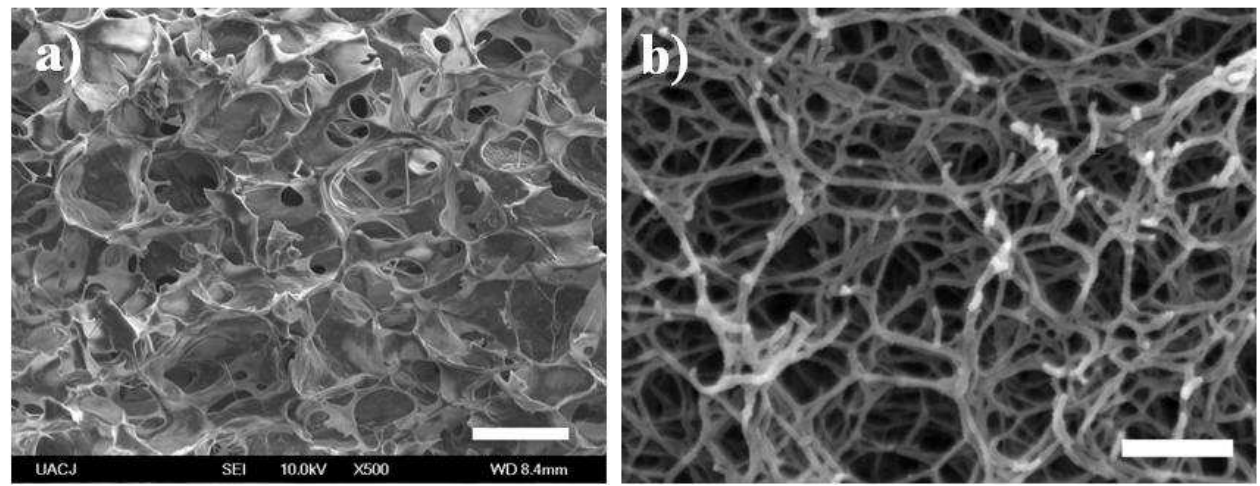

Fig. 1. Hydrogel structures observed by FESEM (Field Emission Scanning Electron

Microscope). a) Chitosan-Glycerophosphate termosensitive hydrogel. Bar $40 \mu \mathrm{m}$. b) Agarose hydrogel. Bar $250 \mathrm{~nm}$.

\subsection{Thermosensitive hydrogels for anticancer drug delivery}

Commonly hydrogels gelatinize when their temperature drops; in other words they are present in a liquid state at higher temperatures, and they solidify when it drops. However, 
there are hydrogels that exhibit the phenomenon of reverse thermal gelation, also known as thermally induced hydrogels. In this case they are liquid at lower temperatures, but they solidify when their temperature rises (Klouda \& Mikos, 2008). This property has been exploited to create hydrogels that remain liquid at temperatures below $30^{\circ} \mathrm{C}$, but they solidify at temperatures close to physiological temperature $\left(37^{\circ} \mathrm{C}\right)$. Therefore, they are better injected subcutaneously as a liquid and solidify when they reach body temperature. Some of these hydrogels are tri-block copolymer synthesized by open-ring polymerization such as poly (ethylene glycol)-poly(epsilon-caprolactone)-poly (ethylene glycol) (PEG-PCLPEG) (ChangYang et al., 2009; Yu, 2009), tri-block copolymer poly(ethylene oxide)-poly (oxidopropileno) -poly (ethylene oxide) (PEO-PPO-PEO) (Li \& Li, 2008), and biopolymer chitosan (C) neutralized with b-glycerophosphate (GP) (Ruel-Gariépy et al., 2004). Most of these hydrogels are studied for drug delivery and some have already been used successfully for this purpose. For example, PEO-PPO-PEO-name Poloxamer 407 has been used to prolong the release of lidocaine (Chen et al., 2004). Also, some natural polymers exhibit the phenomenon of reverse thermal gelation such as those based on chitosan, which have reported positive results; for instance, a solution of chitosan with $40 \%$ weight of PEG has been tested on the release of serum bovine holding a sustained release of at least 70 hours (Bhattarai et al., 2005). Other organic hydrogels with this property are hydroxypropyl cellulose (Cai et al., 2003; Uraki et al., 2004) and methyl cellulose (Kumar et al., 1993).

Among the new methods aimed to replace intravenous chemotherapy for the treatment of tumors there are certain proposals which emphasize the use of temperature-sensitive hydrogels loaded with anticancer drugs. They suggest the injection of the thermosensitive hydrogels containing drug directly into the affected area (tumor), due to its reverse thermal behavior it solidifies inside the body and then the drug is released gradually. The most common proposed systems for Taxol ${ }^{\circledR}$ delivery have been those that offer direct incorporation of the drug into the thermosensitive hydrogel (Chun et al., 2009; Dai et al., 2006; Kasala et al., 2008; Livnat et al., 2005; Marupudi et al., 2007; Ruel-Gariépy et al., 2004; Shi \& Burt, 2004; Woo Sun et al., 2007). Just to mention some examples, the alginate hydrogel with polyethylene glycol (PEG) (Livnat et al., 2005), the hydrogel Dx-g-PCL result of the synthesis of polycaprolactone (PLC) and Dextran (Dextran70 and Dextran 500) (Shi \& Burt, 2004), so as the thermosensitive chitosan-based hydrogel BST-Gel liquid (Marupudi et al., 2007).

\subsection{Paclitaxel crystallization in hydrogels}

We have studied Taxol ${ }^{\circledR}$ crystallization in aqueous solutions and hydrogels (Castro et al., 2010). In both environments Taxol® forms needle-like crystals that grow concentrically forming complex morphologies such as spherulites, in the case of heterogeneous nucleation, or sheaves (axialites) when they are formed by homogeneous nucleation. In solution or gel these crystals can be observed by DIC (Differential Interference Contrast) microscopy or by fluorescent microscopy when they are labeled with a fluorescent dye such as rhodamine, as described in (Castro et al. 2009). Dried they can be analyzed by scanning electron microscopy (Figure 2). solution by heterogeneous nucleation with a Taxol concentration of $50 \mu \mathrm{M}$. Sample was prepared by drying a drop in a TEM (Transmission Electron Microscope) cooper grid and then metalized by sputter coating with a gold-palladium target. a) Bar $2.5 \mu \mathrm{m}, \mathrm{b}$ ) bar $10 \mu \mathrm{m}$. 
The process of crystallization in aqueous solutions and hydrogels is quite similar and we can describe it in few words, Taxol crystallization follows the classical homogeneous nucleation theory. For low supersaturation (low Taxol concentrations), only a small number of crystals nuclei may form whereas for high supersaturation $(>20 \mu \mathrm{M})$ the number of nuclei increases drastically with increasing Taxol@ concentration.
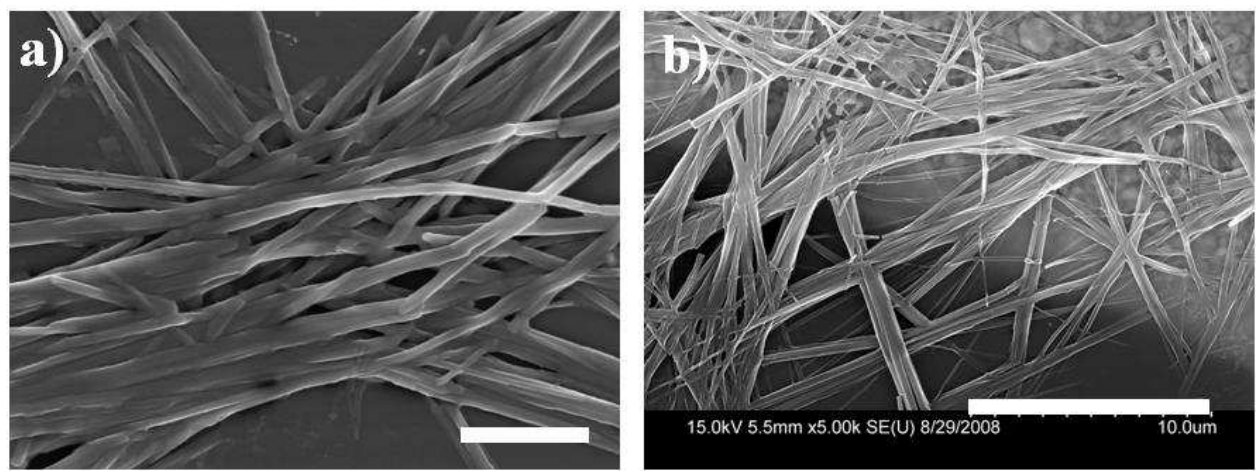

Fig. 2. Taxol crystals observed by FESEM. These crystals were obtained in aqueous solution.

As we mentioned before, the most common Hydrogel-based Taxol@ delivery systems reported in literature suggest the direct incorporation of the drug into the thermosensitive hydrogel (Chun et al., 2009; Dai et al., 2006; Kasala et al., 2008; Livnat et al., 2005; Marupudi et al., 2007; Ruel-Gariépy et al., 2004; Shi \& Burt, 2004; Woo Sun et al., 2007). But nobody, except Shi \& Burt (2004), has reported Taxol crystallizacion in their systems. We claim that this phenomenon is present in most of these works, unfortunately this problem has been a neglected topic by many researchers and may go unnoticed because Taxol® crystals are not detectable by commonly used techniques for the characterization of the hydrogels. Perhaps, researchers have been concerned primarily in designing a good delivery system, neglecting other aspects of the drug, such as its crystallization. In studies reported in the literature that follow this line, no one takes into account, neither they mentioned nor reported studies of crystallization of Taxol ${ }^{\circledR}$ in hydrogels, despite that the use of the drug concentrations is greatly exceeded in its limit of solubility in aqueous solutions $(0.77 \mu \mathrm{M})$ (Shi \& Burt 2004).

In order to provide evidence of Taxol crystallization in these hydrogels we have performed several experiments following similar conditions to that reported in the papers mentioned before. For instance we used similar hydrogels such as agarose, chitosan, poly (L-lactic acid) PLLA and thermosensitive Chitosan-Glycerophosphate and we also used Taxol concentrations similar, or even lower, to that reported in that works. As result we have found that Taxol ${ }^{\circledR}$ crystallization is always present in hydrogels and thermosensitive hydrogels (Figure 3). According to our observations Taxol@ crystallization follows the behavior of the classical homogenous nucleation theory, as mentioned before. That means that at low Taxol concentrations $(<30 \mu \mathrm{M})$ few but big $(15-25 \mu \mathrm{m})$ axialites are present, while at higher many and smaller axialites are observed (Castro et al., 2011). Moreover paclitaxel crystals are very stable in aqueous environments. We have observed these crystals up to two months of formation without any noticeable change. Hence we can speculate that Taxol crystals inside the body probably would last for long time activating immune reactions. 
Direct incorporation of paclitaxel into hydrogels can lead to crystallization of the drug which can dramatically decrease the therapeutic effects and effectiveness of paclitaxel delivery systems. Supporting our theory, we find in the work of Chun (2009) who reported that in vivo experiments with rats, contrary to what would be expected, the hydrogel with a lower concentration of Taxol ${ }^{\circledR}$ was more effective at tumor inhibition than hydrogel with the highest concentration. Although the authors did not provide explanations for such unexpected results, for us a good reason of this fact is the phenomenon of Taxol® crystallization, which is enhanced at higher concentrations. All this experimental evidence could be enough reason to believe that these systems do not meet the desired expectations and require major rethinking.

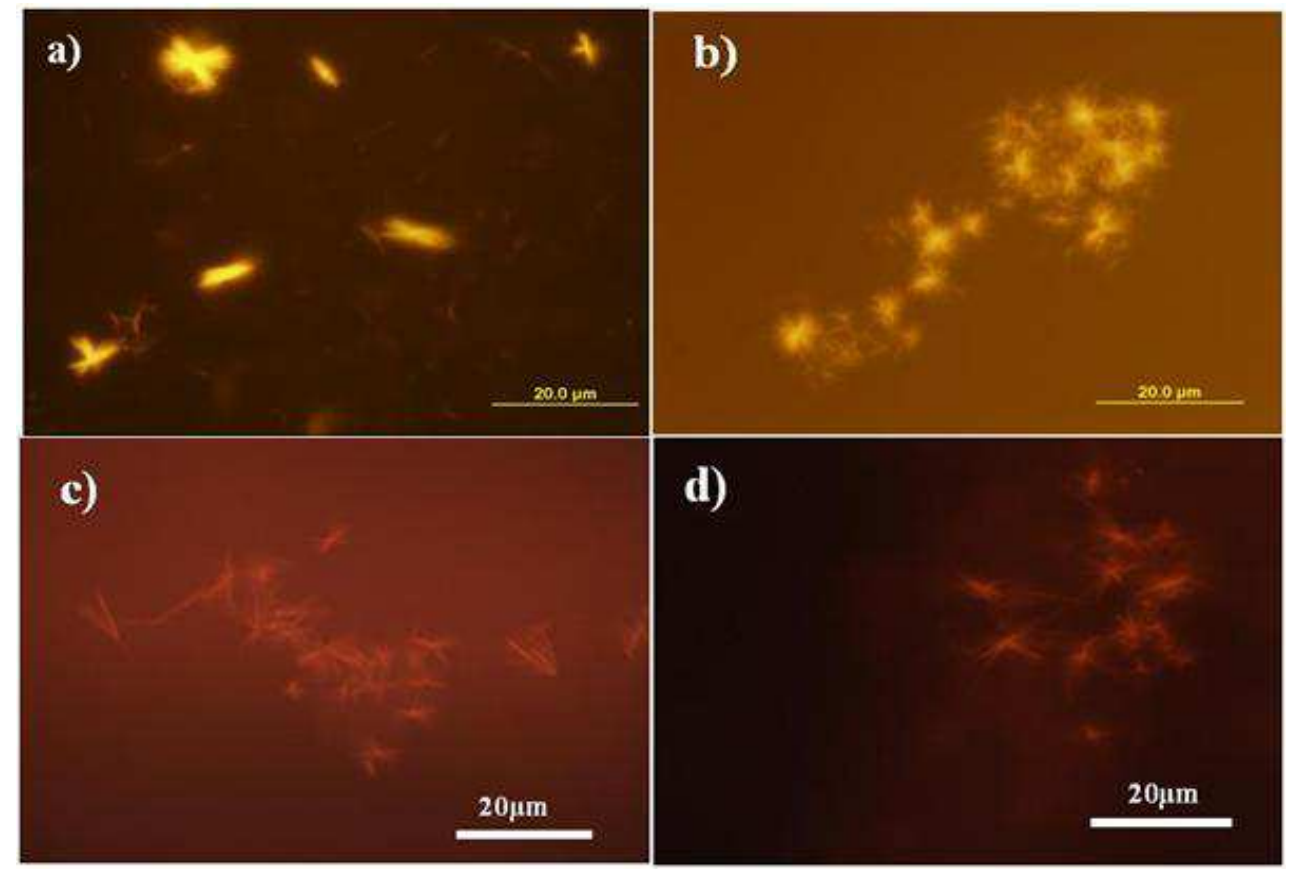

Fig. 3. Taxol crystals formed in hydrogels. a) in aqueous solution, b) in agarose hydrogel, c) in poly (L-lactic acid) hydrogel, d) Chitosan-Glycerophosphate hydrogel. All samples prepared at a paclitaxel concentration of $100 \mu \mathrm{M}$.

\section{Nanoparticles for drug delivery}

In order to minimize the inconvenient of the hydrophobicity many authors have proposed the encapsulation of hydrophobic drugs in nanoparticles, this would allow increasing the amount of drug administered without using nasty solvents such as CrEL in the case of paclitaxel. Thus it is being explored new types of delivery systems based in nanocarriers such as micelles (You et al., 2008), nanoparticles (Liang et al., 2006), thin films (Shi \& Burt, 2004), and microspheres (Liu et al., 2007) among others (Ferrari \& Downing, 2005), whose effectiveness is related to its size, modification of pharmacokinetics, biodistribution, 
delivery control and toxicity reduction (Jun et al., 2008). Each one of these particles has unique characteristics that should be carefully analyzed taking into account the type of drug and the desired interaction to obtain the adequate system delivery. The liposome usage for delivery agent of the anticancer drugs is very broad, such as Doxil ${ }^{\circledR}$, this drug is commercially distributed and used in several ovarian cancer treatments (Gordon et al., 2001). However, the liposomes present several disadvantages due to their high permeability and stability in vivo (Conlin et al., 2009). Dendrimers are macromolecules characterized by their structural monodispersivity and symmetry. They consist of a central nucleus and its diverse ramifications. It contains different functional groups generally located on the exterior, which play an important role in their properties (Caminade et al., 2005). A disadvantage is its difficulty to be synthesized (Tomalia et al., 1990). The dendrimers are used in research studies for the prevention of sexually transmitted diseases (Zolnik \& Sadrieh, 2009), as contrasting agents in Magnetic Resonance Imaging (Zolnik \& Sadrieh, 2009), combined with anticancer drugs (Malik et al., 1999), among other usages. The nanocapsules are vesicular systems with colloidal size, in which the drug is located inside and surrounded by a polymeric membrane (Soppimath et al., 2001). In this system, the nucleus consists of oily liquid and a simple polymeric layer covers it, this system has shown to be effective in encapsulating and releasing certain types of hydrophobic drugs (Ameller et al., 2003). Nanospheres are solid colloidal particles in which the drug can be dissolved, encapsulated, conjugated or absorbed (Gref et al., 1995; Soppimath et al., 2001). They are generally larger than micelles and although its elimination is slow due to its hydrophobicity, are susceptible to renal filtration and the mono nuclear phagocyte system (MPS), It is therefore necessary to modify its surface (Letchford \& Burt, 2007). Good stability has been achieved in nanospheres using amphiphilic copolymers (Gref et al., 1995), so it is possible the encapsulation of the bioactive molecule at the core of the nanosphere (Yanasarn et al., 2009), for example, it has been observed that the nanoparticles synthesized from emulsion of lecithin / water loaded with paclitaxel are more effective in attacking cancer cells than pure paclitaxel (Hu et al., 2009). In another study, gold nanoparticles encapsulated in nanospheres of chitosan and poly (acrylic acid) CS-PAA-Au have been used as delivery system drugs as well as for observation of cells (Latere et al., 2002).

Within this range of particles could not miss the micelles, which have had a great interest in the issue of drug delivery and location into tumors (Lee et al., 2003; Yokoyama et al., 1999). Micelles are amphiphilic molecules consisting of hydrophilic and hydrophobic segments. Its outer layer, which is highly hydrated, provides stability in aqueous environments, while the hydrophobic core allows the incorporation of water-insoluble drugs. Moreover, if the polymeric micelles have a diameter ranging from 10 to $100 \mathrm{~nm}$ allows long circulation in the bloodstream avoiding defenses of the mono nuclear phagocyte system and suppressing renal clearance. They can be large enough to avoid being excreted by the kidneys but small enough to pass the interendothelial cell filtration (Yang et al., 2009).

As a result, drug activity continues after a single application over a long period of time. In addition, these micelles remain intact at levels below the critical micelle concentration $(\mathrm{CMC})$, so they retain their structure and preferentially accumulate in solid tumors via the permeability and retention effect (EPR) (Nakayama et al., 2007; Saez et al., 2004). Its amphiphilic nature gives them a central place in the area of the release of hydrophobic drugs, due to its excellent drug storage capacity in its core. 
The hydrophobic core also has other important features such as protecting the drug from being deactivated by enzymes or other bioactive species from the aqueous medium (blood fluid) (Wilhelm et al., 1991; (Yokoyama et al., 1990). Also, this medium affects the rate of drug release, in many cases declining it, as the release rate is controlled both by the stability of the micelles as the hydrophobicity of their core and the chemical species used to attach the drug to the polymer backbone. These factors may be independent of the properties of the drug.

While each system has its advantages and disadvantages, micelles and nanospheres formed by amphiphilic copolymers have greater flexibility in their synthesis and uses, and they have had good results with hydrophobic drugs. The difference lies in the method of preparation and length of the hydrophobic segment. Although for some authors the nanospheres are systems that perform in vivo by presenting better retention properties of the drug, they have a burst effect when the drug is readily released; in this sense, the nanospheres are overcome by the micelles who exhibit more stable behaviors (Gaucher et al., 2010; Kwon, 2003). We can mention some examples of micelles made of different polymers used to carry drugs. We cite a few micelles synthesized from copolymer PEGPASP-DMEDA loaded with ammonium glycyrrhizate (AMG) poorly water soluble drug used against Hepatitis C (Yang et al., 2009). Copolymer polylactide / polyethylene glycol is synthesized by polymerization of ring-opened was used to encapsulate paclitaxel without the presence of an organic solvent (Kim et al., 2009). Also, some micelles are sensitive to changes in $\mathrm{pH}$, this feature can be used to control drug release as self-assembled micelles of copolymer PEG-b-PMA with divalent metals loaded with doxorucibin ( $\mathrm{Li}$ et al., 2009). Tamoxifen and paclitaxel have also been charged in micelles with a hydrophilic block of poly [2 - (ethyl methacriloyloxi) phosphorylcholine] (MPC), hydrophobic block and a $\mathrm{pH}$ sensitive poly [2 - (diisopropylamine)ethyl methacrylate] (DPA) (FA-MPC-DPA) (Licciardi et al., 2008). Doxorubicin was loaded using thermosensitive blocks such as poly (Nisopropylacrylamide-co-N, N-dimethyl-acrylamide) in which the hydrophobic part was

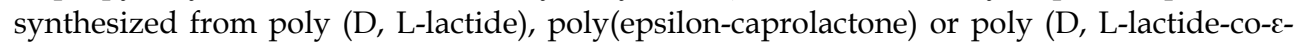
caprolactone) (Masamichi et al., 2006). Another type of thermosensitive micelles have been synthesized from poly (N-isopropylacrylamide) and poly (butyl methacrylate) also loaded with doxorubicin (Chung et al., 1999). Similarly, micelles have been developed and modified in the copolymer as synthesized from poly (ethylene glycol)-poly (aspartateester groups heptyl, nonyl, phenyl propyl benzyl and for greater stabilization of the drug N-(4 hydroxifenil) retinamide (Tomoyuki et al., 2008).

Encapsulation of paclitaxel in nanoparticles is very promising and results have been favorable, judging by the reports in the literature. However, most authors suggest the use of nanoparticles to be injected into the bloodstream, following the route of traditional chemotherapy, which somehow still has the disadvantage of low specificity in which the problem is attacked. But that's not all, perhaps the main problem is not the lack of specificity of the method, but the risk involved in the use of nanoparticles in the bloodstream. Currently, no one knows for sure the adverse effects of the use of nanoparticles in the bloodstream, since its size could pass biological membranes or barriers and it has unknown effects on areas of the body, becoming a health risk factor, as noted by experts on the subject of the risks of nanotechnology in medicine (Scott et al., 2008). To this, we must add that the nanoparticles contain a highly cytotoxic drug. 


\subsection{Functionalization of nanoparticles}

Particle functionalization with specific ligands for cancer cells has gained considerable attention for those looking for more specificity in their systems carrying the drug. Work is being currently done to prove their effectiveness with different ligand-receptor systems in a variety of cancer cell lines to test the efficiency of the functionalization of these systems. The effectiveness of the functionalization of nanoparticles lies in the premise of the existence of certain molecules in tumors are different from those found in normal tissues and can be identified as biomarkers of tumorogenesis (Mohd \& Mohammad, 2009). Depending on its test site, they may be biomarkers of tissue or circulatory. Tissue biomarkers have different categories such as membrane receptors, oncogenes, tumor suppressor genes, nucleic antigens, growth factors and components of degradation. Circulatory biomarkers include a broad category of tumor-associated antigens (TAA). Selective biomarkers can identify risks and help tumor detection, and an early diagnosis allows appropriate therapeutic interventions for an effective treatment. In addition to these biomarkers, it is also common to find an over expression of certain proteins membrane in cancer cells, which has been used for the use of specific ligands or molecules to these proteins, such as folic acid to folate receptors, to obtain greater interaction of nanoparticles to cancer cells. In this case, the effectiveness of the functionalization is more a matter of statistics than specificity by itself, since having the over expression of these receptors will increase the likelihood of attracting a greater number of drug-loaded nanoparticles to diseased cells.

Micelles have been recently reported to have been functionalized with folic acid as a specific ligand, which is strongly attracted to its receptor in the cell membrane. The folate receptor is a protein that is generated in large quantities during cell proliferation in several types of cancer cells such as ovarian, breast, brain and lung (Ross et al., 1994).

Also, peptides have been used for the functionalization of micelles as locators of cancer cells. The nature of polypeptides allows performance optimization of specific ligands by adjusting the sequence or conformation of the peptides. One example is the peptide cRGD (cyclic ArgGly-Asp-D-Phe-Lys) specific for av $\beta 3$ receptor produced in large amounts in tumor endothelial cells (Nasongkla et al., 2004). These receptors are a cell membrane protein that is affected with the growth of tumors, local invasiveness and potentially in metastasis, but it is not detected in quiescent vessels (Rueg et al., 2002; Teti et al., 2002; Vamer \& Cheresh, 1996). This membrane receptor increases its levels in vascular angiogenesis, thus making tumor treatment specific for the generation of new blood vessels (Wermuth et al., 1997). Carbohydrate functionalized micelles, asialoglycoprotein receptor (ASGPR) is a recipient of lecithin membrane commonly found in liver cells (Ashwelland \& Harford, 1982). In hepatocellular carcinoma are high levels of (ASGPR), which helps the specificity of chemotherapy for liver (Wands \& Blum, 1991). Carbohydrate molecules such as galactose and mannose are specific ligands of this receptor (Goto et al., 1994; Jansen et al., 1991).

The use of antibodies as specific ligands is promising as they are able to bind to a range of specific antigens in cancer cells. The combination of a brain-specific antibody increased to 5fold the neuroleptic action in charged micelles than in non-functionalized micelles, and it is 20 times greater than for the free drug (Kabanov et al., 1989). Micelles have been reported (PEG-PE) functionalized with 2 antibodies, a monoclonal anti-cancer antibody (mAb2C5) and anti-myosin (mAb2G4). Both antibodies have great ability to bind to the substrates after conjugation of the micelles. The antibody $2 \mathrm{C} 5$ in micelles loaded with paclitaxel increased 4 times the drug accumulation in the tumor after 2 hours (Torchilin et al., 2003). Furthermore, there is the functionalization of micelles with aptamers. The aptamers are DNA and RNA 
oligonucleotides that can identify a large number of specific molecules (Torchilin et al., 2003; Tuerkand \& Gold, 1990). We have seen that PEG-PLA micelles with an RNA aptamer specifically bind to an antigen on the membrane of prostate tumor (PSMA). Nanoparticles with the induction of aptamer showed 77 times more specificity to PSMA receptor than nonfunctionalized particles (Ellingtonand \& Szostak, 1990). The use of ligands has yielded promising results for the location of cancer cells. This will allow drug release systems based on nanoparticles using different ligands that recognize different types of cancer. There is further research to look for future and further specific treatments with low or no side effects. Instead of using a single ligand, nanoparticles' specificity can be potentiated using multiple ligands in a single particle. Sooner or later, these systems will have the ability to attack different cancers at once or they will be designed to exchange specific ligands in an easy way, having a generic nanoparticle system capable of receiving any desired ligand presenting a universal binding system.

\section{Combined systems based on hydrogels and nanoparticles}

There are few studies that have integrated particles or micelles loaded with Taxol® in thermosensitive hydrogels. As good examples we can mention the system proposed by Jiang Liu et al. (2007) (Liu et al., 2007). This system consists of a biodegradable gelatin sponge containing PLGA-PTX microspheres (polylactide-co-glycolic acid-paclitaxel) in order to provide continuous local release of PTX (paclitaxel). They obtained a more prolonged release rate for up to 19 days, in contrast to simple systems where the paclitaxel was released within a range less than one hour. In another study presented by Yang Yang et al. (2009) joined Docetaxol (DTX) in a pluronic gel F127(PF127) injectable thermosensitive mixed micelles prepared with the same material (PF127) and loaded with Taxol® (system GMM). During a test of 156 hours, it was found that the proposed system maintains a prolonged release of DTX compared with other control systems (Yang et al., 2009).

The development of combined drug delivery systems based on efficient and innovative drug encapsulation in functionalized nanoparticles to detect and attack cancer cells, using thermosensitive hydrogels as vehicles that can be injected locally can be an excellent option for the treatment of cancerous tumors, thereby eliminating the supply of intravenous drugs and consequently the severe side effects. Specifically for Taxol®, its encapsulation in nanoparticles would prevent crystallization when deposited in the hydrogel. In addition, the release rates could be controlled in a double form, both by the action of the degradation of gel particles released and at the same time by the degradation of the particle containing the Taxol@. Achieving prolonged drug release would increase the therapeutic effects for longer periods. An added value to these systems is the funcionalization or even multifuncionalization of nanoparticles with ligands or antibodies for high specificity to cancer cells, which should increase the efficiency and the therapeutic effectiveness of the system. Even today very few researchers have worked with Taxol@ delivery systems with the characteristics listed above; making this theme of the project attractive and innovative for study.

\section{Conclusions}

Researchers are currently exploring new methods for transport and controlled release of drugs for cancer treatment, thereby seeking to reduce the side effects the of currently 
applied chemotherapy as well as looking for battling more efficiently and accurately such disease. Although there are a number of published research focused on this issue, the fact is that so far no systems have emerged to prove conclusively its efficacy, although always positive progress has been shown, each proposed system suffers from certain drawbacks that slows down the progress towards real applications. The disadvantages found in the systems of transport and release of anticancer drugs proposed in recent years can be overcome by taking advantage of each method and combining them into drug delivery systems composed with more sophistication and complexity than their predecessors. This idea has already begun to be implemented by some researchers who have integrated drugloaded nanoparticles on thermosensitive hydrogels (Liu et al., 2007), but these authors have not exploited the alternative of functionalization or multi-functionalization of nanoparticles. So, there is still much room for much improvement in these drug delivery systems and it is where researchers could find novel ideas. For example we can think in to make functionalized or multifunctionalized nanoparticles loaded with a anticancer drug, then incorporate them into a thermosensitive hydrogel. With this proposed system, the hydrogel may be injected into the tumor area (in the case of solid tumors) and gradually functionalized nanoparticles will be released. Due to its functionalization, they will be attracted mainly to diseased cells, nanoparticles will be biodegraded and drug will be released surrounding the cell. There are several advantages of using combined systems. For example, the highly localized application by avoiding the bloodstream, in the case of solid tumors; an improved release profile with a slow and steady dose that highly favored the drug's effectiveness in eliminating cells. The effectiveness of the functionalization of nanoparticles will be favored by the close application to malignant cells; in general, we will expect to acquire treatments where the typical collateral damage observed in common chemotherapies would be considerably lower as well as the required dose.

\section{Acknowledgment}

We want to express our gratitude to Alejandro Martinez and Jorge A. Perez Leon for access to their laboratory and fluorescent microscope supported by CONACYT, Selene Sandoval for sample preparation, Rodolfo Avitia for language assistance and corrections, the University of Arizona and the Autonomous University of Juarez City (UACJ) for the backup and the financial support from PROMEP (Programa para el mejoramiento del profesorado) grant UACJ-EXB-131 and NSF/NIRT grant 0303863.

\section{References}

Ameller,T.; Marsaud, V.; Legrand, P.; Gref, R.; Barratt, G. \& Renoir, J.M. (2003). PolyesterPoly(Ethylene Glycol) Nanoparticles Loades with the Pure Antiestrogen RU 58668: 0 Pysicochemical and Opsonization Properties. Pharm. Res., Vol.20, pp. (1063-1070).

Ashwelland, G. \& Harford, J. (1982). Carbohydrate-specific receptors of the liver. Ann. Rev. Biochem, Vol. 51, pp.(531-554).

Bennett, S.L.; Melanson, D.A.; Torchiana, D.F.; Wiseman, D.M. \& Sawhney, A.S. (2003). Next-Generation HydroGel Films as Tissue Sealants and Adhesion Barriers. Journal of Cardiac Surgery, Vol.18, No. 6, pp.(494-499). 
Bhattarai, N.; Ramay, H.R.; Gunn, J.; Matsen, F.A. \& Zhang, M.Q. (2005). PEG-grafted chitosan as an injectable thermosensitive hydrogel for sustained protein release. Journal of Controlled Release, Vol.103, No.3, pp.(609-624).

Cai, T.; Hu, Z.B.; Ponder, B.; St John, J. \& Moro, D. (2003). Synthesis and study of and controlled release from nanoparticles and their networks based on functionalized hydroxypropylcellulose. Macromolecules.Vol.36, No.17, pp. (6559-6564).

Caminade, A.M.; Laurent. R. \& Majoral, J.P. (2005). Characterization of dendrimers. Advanced Drug Delivery Reviews, Vol.57, pp.(2130-2146).

Castro, J.S. ; Deymier, P.A. ; \& Trzaskowski, B. (2011). Paclitaxel Crystals: Molecular Interactions, Nucleation and Growth, and Possible Implications on Cell Studies. Horizons in Cancer Research, Vol. 45, 5, Editor: Hiroto S. Watanabe, ISBN:978-161209-377-2, Nova Science Publishers, Inc. Hauppauge, New York.

Castro, J. S.; Deymier, P. A.; Trzaskowski, B. \& Bucay, J. (2010). Heterogeneous and homogeneous nucleation of Taxol crystals in aqueous solutions and gels: effect of tubulin proteins. Submitted to Colloids and Surfaces B: Biointerfaces, Vol.76, pp. (199-206)

Castro, J. S.; Trzaskowski B.; Deymier, P. A.; Bucay j.; Adamowicz L.; and Hoying, J. B. (2009). Binding Affinity of Fluorochromes and Fluorescent Proteins to Taxol Crystals. Materials Science and Engineering:C, Vol. 29, pp. (1609-1615).

ChangYang, G.; Shuai, S.; PengWei, D.; Bing, K.; MaLing, G.; XianHuo, W.; XingYi, L.; Feng, L.; Xia, Z.; YuQuan, W. \& ZhiYong, Q. (2009). Synthesis and characterization of PEG-PCL-PEG thermosensitive hydrogel. International Journal of Pharmaceutics, Vol. 365, pp. (89-99).

Chen, P.C., Kohane, D.S., Park, Y.J., Bartlett, R.H., Langer, R. \& Yang, VC. (2004). Journal of Biomedical Materials Research Part A, Vol.70, No.3, pp. (459-466).

Chun, C.; Lee, S.M.; Sang, Y.,K.; Kim, Y.H., \& Song, S.C. (2009). Thermosensitive poly(organophosphazene)-paclitaxel conjugate gels for antitumor applications. Biomaterials, Vol.30, pp.(2349-2360).

Chung, J.E.; Yokoyama M., Yamato M., Aoyagi T., Sakurai Y., Okano T. (1999) Thermoresponsive drug delivery from polymeric micelles constructed using block copolymers of poly( $N$-isopropylacrylamide) and poly(butylmethacrylate). Journal of Controlled Release, 62, pp.(115-127).

Conlin, P.; O’Neil, S. T.; Demurtas, D.; Finka, A. \& Hubbell, J. A. (2009). A Novel Method for the Encapsulation of Biomolecules into Polymersomes via Direct Hydration. Langmuir, Vol.25, No.16, pp.( 9025-9029).

Dai, P.H; Woo Sun, S.; Ji Heung, K. \& Doo Sung, L. (2006). pH/temperature sensitive poly(ethylene glycol)-based biodegradable polyester block copolymer hydrogels. Polymer, Vol.47, pp. (7918-7926).

Ellingtonand A. D. \& Szostak, J. W. (1990). In vitro selection of Rna molecules that bind specifc ligands. Nature, Vol.346, pp.(818-822).

Ferrari, M. \& Downing, G. (2005). Medical nanotechnology: shortening clinical trials and regulatory pathways. BioDrugs, Vol.19, pp.(203-210).

for the controlled release of paclitaxel. International Journal of Pharmaceutics, Vol.271, pp.(167179). 
Gaucher, G.; Marchessault, R.H. \& Leroux, J.C. (2010). Polyester-based micelles and nanoparticles for the parenteral delivery of taxanes. Journal of Controlled Release, Vol.143, pp. (2-12).

Gordon, A.N.; Fleagle, J.T.; Guthrie, D.; Parkin, D.E.; Gore, M.E. \& Lacave, A.J. (2001). Recurrent epithelial ovarian carcinoma: a randomized phase III study of pegylated liposomal doxorubicin versus topotecan. J Clin Oncol, Vol.19, pp.(3312-3322).

Goto, M.; Yura, H.; Chang, C.W.; Kobayashi, A.; Shinoda, T.; Maeda, A.; Kojima, S.; Kobayashi, K. \& Akaike, T. (1994). Lactose-carrying plystyrene as a drug delivery carrier-investigation of body distribution to parenchymal liver-cells using I-125 labeled lactose-carrying polystyrene. J. Control. Release, Vol. 28, pp.(223-233)

Gref, R.; Domb, A.; Quellec, P.; Bluk, T.; Mueller, R.H.; Verbavatz, J.M. \& Langer, R. (1995). The controlled intravenous delivery of drugs using PEG-coated sterically stabilized nanospheres. Adv. Drug Deliv. Rev., Vol.16, pp. (215-233).

Hu, Y.; Chen, Q.; Ding, Y.; Li, R.; Jiang, X. \& Liu, B. (2009). Entering and Lighting Up Nuclei Using Hollow Chitosan-Gold Hybrid Nanospheres. Advanced Materials, Vol.21, pp. (3639-3643).

Jansen, R. W.; Molema, G.; Ching, T. L.; Oosting, R.; Harms, G.; Moolenaar, F.; Hardonk, M, J. \& Meijer, D. K. (1991). Hepatic endocytosis of various types of mannoseterminated albumins. What is important, sugar recognition, net charge, or the combination of these features. J. Biol. Chem., Vol.266, pp(3343-3348).

Jen, A.C.; Wake, M.C. \& Mikos, A.G. (1996). Review: Hydrogels for cell immobilization. Biotechnology and Bioengineering, Vol.50, No.4, pp.(357-364).

Jun, Y. J.; Min, J. H.; Ji, D. E.; Yoo, J. H.; Kim, H. H.; Lee, H. J.; Byeongmoon, J. \& Youn, S.S. (2008). A micellar prodrug of Paclitaxel conjugated to cyclotriphosphazene. Biorganic \& Medical Chemistry Letters, Vol.18, pp.(6410-6414).

Kabanov, A.V.; Checkhonim, V. P.; Alakhov, V. Y.; Batrakova, E. V.; Lebedev, A. S.; Meliknubarov, N. S.; Arzhakov, S. A.; Levashov, A. V.; Morozov, G. V.; Severin E. S. \& Kabanov, V. A. (1989). The neuroleptic activity of haloperidol increases after its solubilization in surfantant micelles-micelles as microcontainers for drug targeting. FEBS Lett., Vol. 258, pp.(343-345).

Kasala, D.; Chaoliang, H. \& Doo Sung, L. (2008). In situ gelling aqueous solutions of pHand temperature-sensitive poly(ester amino urethane). Polymer, Vol.49, pp.(46204625).

Kim, J. O.; Kabanov, A. V. \& Bronich, T. K. (2009). Polymer micelles with cross-linked polyanion core for delivery of a cationic drug doxorubicin. Journal of Controlled Release, Vol.138, pp. (197-204).

Klouda, L. \& Mikos, A. G.. (2008) Thermoresponsive hydrogels in biomedical applications. European Journal of Pharmaceutics and Biopharmaceutics (68), pp.(34-45)

Kumar, G.N.; Walle, U.K.; Bhalla, K.N. \& Walle, T. (1993). Binding of taxol to human plasma, albumin and a 1-acid glycoprotein. Res. Commun. Chem. Pathol Pharmacol, Vol. 80, No.3, pp. (337-334).

Kwon, G.S. (2003). Polymeric micelles for delivery of poorly watersoluble compounds. Crit. Rev. Ther. Drug Carr. Syst., Vol.20, pp. (357-403).

Latere, J.P.; Lecomte, P.; Dubois, P. \& Jerome, R. (2002). 2-Oxepane-1,5-dione: A Precursor of a Novel Class of Versatile Semicrystalline Biodegradable (Co)polyesters. Macromolecules, Vol.35, No.21, pp. (7857-7859). 
Lee, E.S.; Na, K. \& Bae, Y.H. (2003). Polymeric micelles for $\mathrm{pH}$ and foalte-mediated targeting. J. Controlled Release, Vol. 91, pp. (13-103).

Lee, K.Y. \& Mooney, D.J. (2001). Hydrogels for tissue enginnering. Chemical Reviews, Vol.101, No.7, pp.(1869-1880).

Letchford, K. \& Bur,t H. (2007). A review of the formation and classification of amphiphilic block copolymer nanopaticulate structures: micelles, nanospheres, nanocapsules and polymersomes. European Journal of Pharmaceutics and Biophamaceutics., Vol.65, pp. (26-259).

Li, J.; Zhan, Y.; Chen, J.; Wang, C. \& Lang, M. (2005). Preparation, Characterization and Drug Release Behavior of 5-Fluorouracil Loaded Carboxylic Poly(-caprolactone) Nanoparticles. Journal of Macromolecular Science, Part A, Vol.104, No.3, pp. (477-488).

Li X. and Li J. (2008). Supramolecular hydrogels based on self-assembly betweenPEO-PPOPEO triblock copolymers and a-cyclodextrin. Journal of Biomedical Materials Research Part A, Vol. 86A, No. 4, pp. (1055-1061).

Liang, H.F., Chen, S.C., Chen, M.C., Lee, P.W., Chen, C.T., Sung, H.W., (2006)PaclitaxelLoaded Poly(y-glutamic acid)-poly(lactide) Nanoparticles as a Targeted Drug Delivery System against Cultured HepG2 Cells. Bioconjugate Chemistry. Vol.17, No.2, pp.( 291-299).

Licciardi, M.; Craparo, E. F. ; Giammona, G. ; Armes, S. P. ; Tang, Y. ; Lewis, A.L. (2008). In vitro Biological Evaluation of Folate-Functionalized Block Copolymer Micelles for Selective Anti-Cancer Drug Delivery. Macromol. Biosci. Vol. 8, (615-626).

Liu, J.; Meisner, D.; Kwong, E.; Xiao Y. W. \& Johnston, M.R. (2007). A novel trans-lymphatic drug delivery system: Implantable gelatin sponge impregnated with PLGApaclitaxel microspheres. Biomaterials, Vol.28, pp.(3236-3244).

Livnat, M.; Beyar, R. \& Dror, S. (2005). Endoluminal hydrogel films made of alginate and polyethylene glycol: Physical characteristics and drug-eluting properties. Wiley InterScience. Vol. 75, No.3, pp. (710-722).

Malik, N.; Evagorou, E.G., Duncan, R. (1999). Dendrimer-platinate: a novel approach to cancer chemotherapy. Anticancer Drugs, Vol. 10, pp. (76-767).

Marupudi, N.I.; Han, J.E.; Li, K.W., Renard, V.M.; Tyler, B.M. \& Brem, H. (2007. Paclitaxel: a review of adverse toxicities and novel delivery strategies. Expert Opin. Drug Saf. Vol.6, No.5, pp.(609-621).

Masamichi, N.; Teruo,O.; Takanari, M.; Fukashi, K.; Kiyotaka,S. \& Masayuki, Y. (2006). Molecular design of biodegradable polymeric micelles for temperature-responsive drug release. Journal of Controlled Release, Vol. 115, pp.(46-56).

Nakayama, M.; Chung, J.E.; Miyazaki, T., Yokoyama, M.; Sakai, K. \& Okano, T. (2007). Thermal modulation of intracellular drug distribution using thermoresponsive polymeric micelles. Reactive E Functional Polymers, Vol. 67, pp. (1398-1407).

Nasongkla, N.; Shuai, X.; Ai, H.; Weinberg, B.D.; Pink, J.; Boothman, D.A. \& Gao, J. M. (2004) cRGD-functonalized polymer micelles for target doxorubicin delivery. Angewandle chemie-international Edition, Vol.43, pp.(6323-6327).

receptor isoforms in normal and malignant tissues in vivo and in establish cell-lines physiological and clinical implications. Cancer, Vol.73, pp.(2432-2443).

Ross, J. F.; Chaudhuri, P. K. \& Ratnam, M. (1994). Differential regulation of folate receptor isoforms in normal and malignant tissues in vivo and in establish cell-lines physiological and clinical implications. Cancer.73, pp.(2432-2443). 
Rowinsky, E.K., Donehower, R.C. (1995). Paclitaxel (Taxol). New Engl. J. Med, Vol.332, No.15, pp.(1004-1014).

Rowinsky, E.K.; Cazenave, L.A. \& Donehower, R.C. (1990). Taxol: A Novel Investigational Antimicrotubule Agent. J. Natl. Cancer I. Vol.82, pp.(1247-1259).

Ruegg, C.; Dormond, O. \& Foletti, A. (2002). Suppression of tumor angiogenesis through the inhibition of integrin function and signaling in endothelial cells: which side to target? Endotheliun. Journal, Vol.9, pp.(151-160).

Ruel-Gariépy, E.; Shive, M.; Bichara, A.; Berrada, M.; Le Garrec, D.; Chenite, A. \& Leroux, J.C. (2004). A thermosensitive chitosan-based hydrogel for the local delivery of paclitaxel. European Journal of Pharmaceutics and Biopharmaceutics, Vol.57, pp. (53-63).

Schiff, P.B.; Fant, J.; Hortwitz S.B. (1979) Promotion of microtubule assembly in vitro by taxol. Nature, 227, 5698, (665).

Scott, W.; Balbus, J. M.; Denison, R.; \& Florinim, K. (2008). Nanotechnolgoy: getting it right the first time. Journal of cleaner production, Vol.16, pp.(1018-1020).

Shi, R. \& Burt, H. M. (2004). Amphiphilic dextran-graft-poly(epsilon-caprolactone) films International journal of pharmaceutics. Vol. 271, No. 1-2, pp.(167-179).

Soppimath, K.S.; Aminabhavi, T.M.; Kulkarni, A.R. \& Rudzinski, W.E. (2001). Biodegradable polymeric nanoparticles as drug delivery devices. J. Controlled Release, Vol. 70, pp. (1-20).

Teti, A.; Migliaccio, S. \& Baron. R. (2002). The role of the alphaVbeta3 integrin in the development of osteolityc bone metastases: a pharmacological target for alternative therapy? Calcif.Tissue Int.Journal, Vol.71, pp.(293-299).

Tomalia, D.A.; Naylor, A.M. \& Goddard, W.A. (1990). Starburst dendrimers: molecular-level control of size, shape, surface chemistry, topology and flexibility in the conversion of atoms to macroscopic materials. Angew, Chem. Int., Vol.102, No.2, pp.(119-157).

Tomoyuki, O.; Shigeru, K.; Masayuki, Y.; Tatsuhiro, Y.; Fumiyoshi, Y. \& Mitsuru, H. (2008). Block copolymer design for stable encapsulation of $\mathrm{N}-(4-$ hydroxyphenyl)retinamide into polymeric micelles in mice. International Journal of Pharmaceutics, Vol.37, pp.(318-322).

Torchilin, V. P.; Lukyanov, A, N.; Gao, Z. \& Papahadjopoulos-Sterberg, B. (2003). Immunomicelles: targeted pharmaceutical carriers for poorly soluble drugs. Proc. Natl. Acad. Sci. USA., Vol. 100, pp.(6039-6044).

Tuerkand, C. \& Gold, L. (1990). Systematic evolution of ligands by exponential enrichmentRna Ligands to Bacteriophage-T4 DNA-Polymerase. Science, Vol. 249, pp.(505-510).

Uraki, Y.; Imura, T.; Kishimoto, T. \& Ubukata, M. (2004). Body temperature-responsive gels derived from hydroxypropylcellulose bearing lignin. Carbohydrate Polymers. Vol.58, No.2, pp.(123-130).

Van Der Linden, H.J.; Herber, S.; Olthuis, W. \& Bergveld, P. (2003). Stimulus-sensitive hydrogels and their applications in chemical (micro) analysis. Analyist, Vol. 128, No.4, pp. (325-331).

Varner, J. A. \& Cheresh, D. A. (1996). Tumor angiogenesis and the role of vascular cell integrin alphavbeta3. Important Adv. Oncol., pp.(69-87).

Wands, J. R. \& Blum, H. E. (1991). Primary Hepatocelluar carcinoma. N. Engl. J. Med., Vol. $325, \operatorname{pp}(729-731)$. 
Wang, J.; Loup, P.; Lesnieswki, R. \& Henkin, J. (2003). Placlitaxel at ultra low concentrations inhibits angiogenesis without affecting cellular microtubule assembly. Anticancer Drugs. Vol.14, No.1, pp.(13-19).

Wang, K.; Burban, J. \& Cussle, E. (1993). Hydrogels as separation agents. Advances in polymer science. Vol. 110, pp.(67-79).

Wani., M.C., Taylor, H.L., Wall, M.E., Coggon, P., McPhail. A.T., (1971) Plant antitumor agents. VI. Isolation and structure of taxol, a novel antileukemic and antitumor agent from Taxus brevifolia. J. Am. Chem. Soc., Vol. 93, pp.( 2325).

Weiss, R.B.; Donehower, R.C. \& Wiernik, P.H. (1990). Hypersensitivity reactions from taxol. J. Clin. Oncol. Vol.8, No.7, pp.(1263-1268).

Wermuth, J.; Goodman, S. L.; Jonczyk, A. \& Kessler, H. (1997). Stereoisomerism and biological activity of the selective and superactive alpha(v)beta(3) integrin inhibitor cyclo(-RGDfV-) and its retro-inverso peptide. J. Am. Chem. Soc., Vol.119, pp.(13281335).

Wiernik, P.H.; Schwartz, E.L. \& Strauman, J.J. (1987) Phase I clinical and pharmacokinetic study of taxol. Cancer Res. Vol. 47, No.9, pp.(2486-2493).

Wilhelm, M.; Zhao, C.L.; Wan, Y.; Xu, R. \& Winnik, M.A. (1991). Poly(styrene-ehylene oxide) Block Copolymer Micelle Formation in Water: A Fluorescence Probe Study. Macromolecules, Vol.24, pp. (1033-1040).

Woo Sun, S.; Jong-Ho, K.; Kwangmeyung, Kim.; Yoo-Shin, Kim.; Rang-Woon, Park.; In-San, Kim.; Ick Chan, Kwon. \& Doo Sung, Lee. (2007). pH-and temperature sensitive injectable biodegradable block copolymer hydrogels as carriers for paclitaxel. International Journal of Pharmaceutics, Vol.331, pp. (11-18).

Yanasarn, N.; Sloat, B.R. \& Cui, Z. (2009). Nanoparticles engineered from lecithin-in-water emulsions as a potential delivery system for docetaxe. International Journal of Pharmaceutics., Vol. 379, pp. (174-180).

Yang, D.; Zhang, X.; Yuan, L. \& Hu, J. (2009). PEG-g-poly(aspartamide-co-N,Ndimethylethylenediamino aspartamide): Synthesis, characterization and its application as a drug delivery system. Progress in Natural Science., Vol.19, pp. (13051310).

Yang, L.; Wu, X.; Liu, F.; Duan, Y. \& Li, S. (2009). Novel Biodegradable Polylactide/poly(ethylene glycol) Micelles Prepared by Direct Dissolution Method for Controlled Delivery of Anticancer Drugs. Pharmaceutical Research, Vol.26, No.10, pp. (2332-2342).

Yang, Y.; JianCheng, W.; Xuan, Z.; WangLiang, L. \& Qiang, Z. (2009). A novel mixed micelle gel with thermo-sensitive property for the local delivery of docetaxel. Journal of Controlled Release, Vol.135, pp.(175-182).

Yokoyama, M.; Okano, T.; Sakuri, Y.; Fukushima, S.; Okamoto, K. \& Kataoka, K. (1999). Selective delivery of adriamicin to a solid tumor using a polymeric micelle carrier system. J. Drug Targeting,Vol. 7, pp. (86-171).

Yokoyama, M.; Miyauchi, M.; Yamada, N.; Okano, T. \& Sakuri, Y. (1990). Polymer Micelles as novel drug carrier: Adriamycin-conjugated Poly(ethylene glycol)-Poly(aspartic acid) block copolymer. Journal of Controlled Release, Vol.11, pp. (269-278).

You, J.; Li, X. ; Cui, F. ; Du, Y.Z. ; Yuan, H. \&Hu, F.Q. (2008). Folate-conjugated polymer micelles for active targeting to cancer cells: preparation, in vitro evaluation of targeting ability and cytotoxicity. Nanotechnology. Vol.19, pp.(9), ISSN 045102. 
Yu, Tang. (2009). Jagdish Singh.Biodegradable and biocompatible thermosensitive polymer based injectable implant for controlled release of protein. International Journal of Pharmaceutics, Vol. 365. (34-43).

Zolnik, B. S. \& Sadrieh, N. (2009). Regulatory perspective on the importance of ADME assessment of nanoscale material containing drugs. Advanced Drug Delivery Reviews, Vol.61, pp.( 422-427). 


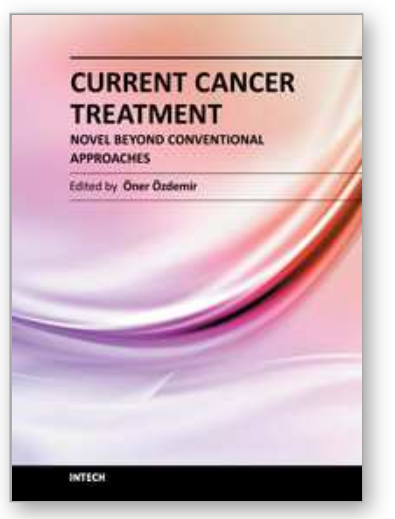

\author{
Current Cancer Treatment - Novel Beyond Conventional \\ Approaches \\ Edited by Prof. Oner Ozdemir
}

ISBN 978-953-307-397-2

Hard cover, 810 pages

Publisher InTech

Published online 09, December, 2011

Published in print edition December, 2011

Currently there have been many armamentaria to be used in cancer treatment. This indeed indicates that the final treatment has not yet been found. It seems this will take a long period of time to achieve. Thus, cancer treatment in general still seems to need new and more effective approaches. The book "Current Cancer Treatment - Novel Beyond Conventional Approaches", consisting of 33 chapters, will help get us physicians as well as patients enlightened with new research and developments in this area. This book is a valuable contribution to this area mentioning various modalities in cancer treatment such as some rare classic treatment approaches: treatment of metastatic liver disease of colorectal origin, radiation treatment of skull and spine chordoma, changing the face of adjuvant therapy for early breast cancer; new therapeutic approaches of old techniques: laser-driven radiation therapy, laser photo-chemotherapy, new approaches targeting androgen receptor and many more emerging techniques.

\title{
How to reference
}

In order to correctly reference this scholarly work, feel free to copy and paste the following:

Javier S. Castro, Lillian V.Tapia, Rocio A. Silveyra, Carlos A. Martinez and Pierre A. Deymier (2011). Negative Impact of Paclitaxel Crystallization on Hydrogels and Novel Approaches for Anticancer Drug Delivery Systems, Current Cancer Treatment - Novel Beyond Conventional Approaches, Prof. Oner Ozdemir (Ed.), ISBN: 978953-307-397-2, InTech, Available from: http://www.intechopen.com/books/current-cancer-treatment-novelbeyond-conventional-approaches/negative-impact-of-paclitaxel-crystallization-on-hydrogels-and-novelapproaches-for-anticancer-drug-

\section{INTECH}

open science | open minds

\section{InTech Europe}

University Campus STeP Ri

Slavka Krautzeka 83/A

51000 Rijeka, Croatia

Phone: +385 (51) 770447

Fax: +385 (51) 686166

www.intechopen.com

\section{InTech China}

Unit 405, Office Block, Hotel Equatorial Shanghai

No.65, Yan An Road (West), Shanghai, 200040, China 中国上海市延安西路65号上海国际贵都大饭店办公楼405单元

Phone: +86-21-62489820

Fax: +86-21-62489821 
(C) 2011 The Author(s). Licensee IntechOpen. This is an open access article distributed under the terms of the Creative Commons Attribution 3.0 License, which permits unrestricted use, distribution, and reproduction in any medium, provided the original work is properly cited. 